\title{
Article
}

\section{Health-Related Quality of Life Norm Data of the Peruvian Adolescents: Results Using the EQ-5D-Y}

\author{
Roxana Paola Palacios-Cartagena ${ }^{1}$, Jose Carmelo Adsuar ${ }^{1, *} * \mathbb{D}$, Miguel Ángel Hernández-Mocholí ${ }^{2}$, \\ Jorge Carlos-Vivas ${ }^{1}\left(\mathbb{D}\right.$, Sabina Barrios-Fernández ${ }^{3} \mathbb{D}$, Miguel Angel Garcia-Gordillo ${ }^{4} \mathbb{D}$ \\ and María Mendoza-Muñoz ${ }^{1}$ (D)
}

Citation: Palacios-Cartagena, R.P. Adsuar, J.C.; Hernández-Mocholí, M.Á.; Carlos-Vivas, J.; BarriosFernández, S.; Garcia-Gordillo, M.A.; Mendoza-Muñoz, M. Health-Related Quality of Life Norm Data of the Peruvian Adolescents: Results Using the EQ-5D-Y. Int. J. Environ. Res. Public Health 2021, 18, 8735. https:// doi.org/10.3390/ijerph18168735

Academic Editors: Momcilo Jankovic and Paul B. Tchounwou

Received: 15 July 2021

Accepted: 16 August 2021

Published: 19 August 2021

Publisher's Note: MDPI stays neutral with regard to jurisdictional claims in published maps and institutional affiliations.

Copyright: (c) 2021 by the authors. Licensee MDPI, Basel, Switzerland This article is an open access article distributed under the terms and conditions of the Creative Commons Attribution (CC BY) license (https:// creativecommons.org/licenses/by/ $4.0 /)$
1 Promoting a Healthy Society Research Group (PHeSO), Faculty of Sport Sciences, University of Extremadura, 10003 Cáceres, Spain; ropalacio@alumnos.unex.es (R.P.P.-C.); jorgecv@unex.es (J.C.-V.); mamendozam@unex.es (M.M.-M.)

2 Physical Activity and Quality of Life Research Group (AFYCAV), Faculty of Sport Science, University of Extremadura, 10003 Cáceres, Spain; mhmocholi@unex.es

3 Social Impact and Innovation in Health (InHEALTH), University of Extremadura, 10003 Cáceres, Spain; sabinabarrios@unex.es

4 Universidad Autónoma de Chile, Sede Talca 3467987, Chile; miguel.garcia@uautonoma.cl

* Correspondence: jadssal@unex.es

Simple Summary: Health-related quality of life in the adolescent stage is of vital importance because it provides the adolescent with an impression of his or her functional capacity, allowing him or her to examine, discover, and distinguish sensations and concerns. This indicator provides information on the person's state of health. The EQ-5D-Y questionnaire was used to measure health-related quality of life, due to its simplicity and ease of use. Therefore, the aim of the present study was to describe the perceived quality of life in Peruvian school adolescents. Despite the increase in health-related quality of life studies, there is little research on the Latin American population. For this reason, it would be important to have normative data in Peru in order to estimate the impact on health-related quality of life in adolescents, since it allows comparisons of health-related quality of life between the general population and the pathological population. The results have shown that there are differences in the EQ-5D-Y between ages, as well as between weight groups established according to body mass index. In conclusion, adolescents have perceived favorable health-related quality of life sensations and the EQ-5D-Y has shown to be a feasible and useful questionnaire, in addition to having internationally recognized and validated cross-cultural characteristics.

Abstract: (1) Introduction: There is a growing interest in health-related quality of life (HRQOL) in adolescent population. The EQ-5D-Y is a generic HRQOL instrument that allows adolescents to understand the health status of different levels of physical, mental, and social health. This study was carried out with an adolescent population in Peru. The main objective of this article is to report the normative values of the EQ-5D-Y questionnaire in Peruvian adolescents. (2) Methods: The EQ-5D-Y questionnaire was administered to Peruvian adolescent students. A total of 1229 young people participated in the survey. The EQ-5D-Y score was reflected as a function of sex and age. (3) Results: The mean utility index of the EQ-5D-Y for the total sample was 0.890 ; this rating was significantly better for males at (0.899) and females at (0.881). The ceiling effect was higher for adolescent males with (47.3) females (40.7). (4) Conclusions: The results of the present study provide evidence that schooled adolescents show a positive perception of HRQOL.

Keywords: adolescents; EQ-5D-Y; health conditions; health-related quality of life (HRQOL); health status assessment

\section{Introduction}

In recent decades, the public health sector has seen a growing interest in research and evaluation of health-related quality of life (HRQOL), as an indicator of physical and mental 
well-being in children and adolescents, providing information on morbidity and mortality measures in public health focused on symptoms and signs of disease rather than subjective assessment of the child/adolescent's functioning and well-being [1].

When a HRQOL's questionnaire is applied in adolescents, it allows them to have a perception about their functional capacity, in which they can observe, detect, and discriminate sensations and concerns. This indicator allows them to discover different aspects of health, at different levels of physical, psychological, and social well-being of young people [2], due to the fact that the quality of life at this stage is closely related to the quality of life in adulthood. For these reasons, the components of HRQOL should receive special attention in pediatric and adolescent care [3].

The measurement of HRQOL requires questionnaires that can be administered quickly and simply, and allow reliable and valid results to be received. Several questionnaires with these characteristics exist today. From its conception, the EuroQol-5D (EQ-5D-3L) was created as a generic and standardized questionnaire, which is simple to answer. It also includes a visual analogue scale (VAS) where the respondent rates his or her own general health on a scale ranging from 0 (worst imaginable health) to 100 (best imaginable health); this is known as the EQ-VAS value and directly reflects the HRQOL as rated by the respondents. This instrument is widely used throughout the world and is available in more than 170 languages [4]. It is feasible to assess the HROoL of the population, given that it is easy to use and intended to provide valid and reliable information [5]. The EuroQol Group perceived a growing interest in assessing HRQOL in younger people, which was a suitable measure for children and adolescents, creating the EQ-5D-Y instrument. This was developed on behalf of the EuroQol Group in the year 2009/2010 by a team of researchers from 7 countries (Germany, Italy, South Africa, Spain, Sweden, Holland, and United Kingdom) [6]. This version for children and young people is the most internationally used HRQOL's questionnaire among children and adolescents [7].

Data obtained from this questionnaire in a general population (normative values) allows comparisons of HRQOL with other pathological populations, providing information on specific domains that differ between subjects with or without symptoms to address during treatment or compare patient profiles with particular conditions, including similar age group or gender, aiding health policy development and planning [8].

There are numerous publications on the normative data of the EQ-5D-5L and EQ-5D3L questionnaire among adults in European countries such as Spain [9], Denmark [10], Germany [11], Portugal [12], and United Kingdom [13]. In another continents, there are publications in Japan [14], Australia [15], Hong-Kong [16], and Russia [17]. However, the establishment of normative values in children/adolescents has only been published in Japan [18]. These data can be used in cost-effectiveness analyses, as they are based on healthy individuals. In addition, it should be noted that the population norms for children/adolescents (obtained using the EQ-5D-Y) and adults (obtained using the EQ-5D or EQ-5D-5L) are likely to differ, so it is important to have reference data for each population.

Despite the increase in HRQOL studies, there are few studies aimed at the Latin American population, particularly in an epidemiological and instructional setting [19]. Therefore, having normative data of children/adolescents in Peru could be of interest to estimate the impact on HRQOL in adolescent school students as a useful resource to interpret self-reported outcomes, compare HRQOL assessment results within different populations, determine health deviations, measure inequalities, as well as improve health care, and guide clinicians in planning specific interventions. To our knowledge, there is no study in which the EQ-5D-Y instrument has been used in children/adolescents in Peru, therefore, the aim of this study was to describe the perceived quality of life in Peruvian schooled children/adolescents.

\section{Materials and Methods}

\subsection{Design}

A single-measure cross-sectional study was conducted. 


\subsection{Ethical Approval}

Ethical approval was granted by the bioethics and biosafety committee of the University of Extremadura on 10 December 2020 (approval number: 162/2020), in accordance with the updates of the Declaration of Helsinki, as modified by the 64th General Assembly of the World Medical Association. Association (Fortaleza, Brasil, 2013) and the Law 14/2007 on Biomedical Research.

\subsection{Partipants}

Data collection was performed in school or extracurricular sports activities. Through the cell phone, students accessed the survey link by completing the questionnaire. All participants met the following inclusion criteria: (1) age between 12 and 18 years; (2) informed consent signed by parents or legal guardians; and (3) acceptance of the participant in the study.

The total sample consisted of 1229 adolescent students, of which 622 were female $(50 \%)$ and 607 were male $(50 \%)$, aged 12 to 18 years with a mean age of $14.62( \pm 1.64)$. The follow figure (Figure 1) shows the recruitment process.

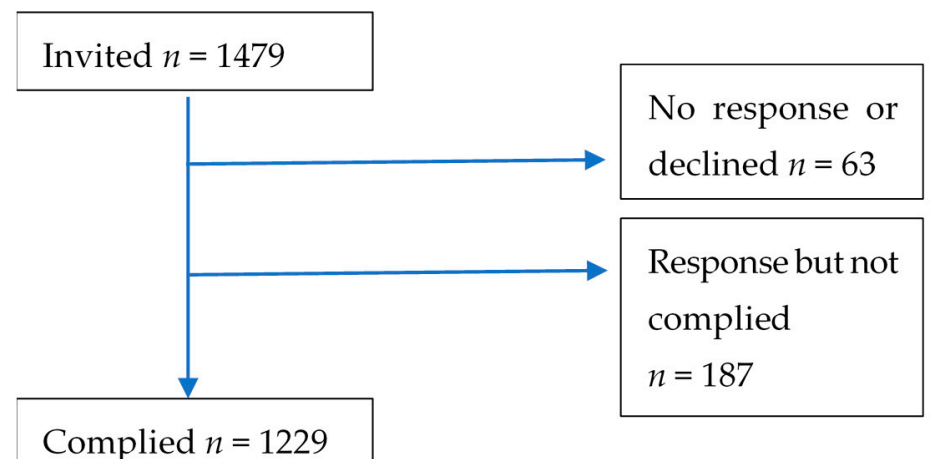

Figure 1. Recruitment process.

\subsection{Measures}

The sociodemographic characteristics collected in the survey were age, sex, weight, height, and educational level.

\subsection{Instrument}

The EQ-5D-Y is a self-administered questionnaire intended to measure the selfperceived health status of adolescents. The Spanish version of the EQ-5D-Y [7] questionnaire and its Proxy version [20] comprise a descriptive section of five dimensions (mobility, self-care, usual activities, pain/discomfort, and anxiety/depression) and each one contains three levels where the person must indicate the severity according to his or her health status at the time of completing the questionnaire [21]. This measure has been tested in various pathologies, and has been able to prove the validity of the instrument in certain areas and track the progress of patients (children and adolescents) through an illness or treatment [22]. Therefore, it can be considered a short instrument, simple to complete, and generic, as it does not refer to any specific disease [23].

\subsection{Statistical Analysis}

All information collected was tabulated in a database designed specifically for this study. Statistical analyses were carried out using IBM SPSS Statistics (Version 25, IBM SPSS, Chicago, IL, USA) and personal data were kept anonymous.

Data were presented as the median and interquartile range both for the total sample and segmented by sex, age, and bodyweight category. Normality and homogeneity were tested using the Kolmogorov-Smirnov test and Levene's test, respectively. 
The Mann-Whitney U test was applied to analyze between sex differences. Chi-square was used for multiple-comparisons in categorical variables (age and bodyweight category).

The ceiling effect was calculated as the percentage of participants who obtained the best possible health status (11111).

The EQ-5D-Y utility index was computed using a regression model according to valuation study specifications reported by Badia, et al. [24].

\section{Results}

Table 1 shows the main characteristics of the study. A total of 1229 Peruvian adolescents participated in the study. Of these, 622 were female and 607 were male. The EQ-5D-Y utility index for the total sample was 0.890 . This score was significantly significant $(p=0.027)$ for males $(0.899)$ than for females $(0.881)$. The ceiling effect was higher for men $(47.3 \%)$ than for women $(40.7 \%)$. However, the ceiling effect experienced a reduction as the age of adolescent students increased with the exception of 17 years old. In addition, statistically significant differences were detected in the EQ-5D-Y utility index between ages, as well as between weight groups established according to BMI.

Table 1. Sample characteristics. EQ-5D-Y adolescents' population normative values.

\begin{tabular}{|c|c|c|c|c|c|c|c|c|c|}
\hline & \multirow[b]{2}{*}{$n$} & \multicolumn{6}{|c|}{ EQ-5D-Y Utility Index } & \multicolumn{2}{|c|}{ Ceiling Effect } \\
\hline & & $(\%)$ & Mean & SD & Median & RI & $p$ & $n$ & $(\%)$ \\
\hline Total & 1229 & 100 & 0.890 & 0.165 & 0.938 & 0.152 & & 540 & 43.9 \\
\hline \multicolumn{10}{|l|}{ Gender } \\
\hline Female & 622 & 50.6 & 0.881 & 0.176 & 0.938 & 0.151 & $0.027^{a}$ & 253 & 40.7 \\
\hline Male & 607 & 49.4 & 0.899 & 0.154 & 0.938 & 0.151 & & 285 & 47.3 \\
\hline \multicolumn{10}{|l|}{ Age } \\
\hline 12 & 200 & 16.3 & 0.897 & 0.201 & 1 & 0.890 & & 129 & 64.5 \\
\hline 13 & 200 & 16.3 & 0.917 & 0.150 & 1 & 0.151 & & 117 & 58.5 \\
\hline 14 & 200 & 16.3 & 0.886 & 0.175 & 0.938 & 0.151 & $<0.001^{b}$ & 88 & 44.0 \\
\hline 15 & 200 & 16.3 & 0.857 & 0.187 & 0.938 & 0.222 & & 59 & 29.5 \\
\hline 16 & 212 & 17.2 & 0.896 & 0.107 & 0.938 & 0.151 & & 62 & 29.2 \\
\hline 17 & 217 & 17.7 & 0.885 & 0.157 & 0.938 & 0.222 & & 85 & 39.2 \\
\hline \multicolumn{10}{|l|}{ IMC Category } \\
\hline Low weight & 6 & 5 & 0.905 & 0.102 & 0.938 & 0.222 & & 2 & 33.3 \\
\hline Normal weigh & 584 & 47.5 & 0.892 & 0.149 & 0.938 & 0.151 & & 225 & 38.5 \\
\hline Overweigh & 527 & 42.9 & 0.904 & 0.155 & 1 & 0.151 & $<0.001^{b}$ & 264 & 50.1 \\
\hline Obesity & 112 & 9.1 & 0.811 & 0.254 & 0.938 & 0.285 & & 49 & 43.8 \\
\hline
\end{tabular}

We can observe in Table 2 that the EQ-5D-Y utility index of the sample segmented by sex, according to age and BMI category. When analysing the results by age groups, it can be seen that 13-year-old adolescents reported the highest mean utility at 0.931 . However, the lowest group included 12-year-old males with a mean of 0.886 . The 12-year-old females showed a mean of 0.908 , being the highest; and the 15 year old group showed a mean of 0.842 , being the lowest in the female age group. It can also be observed that the highest ceiling effect is found at the age of 12 years in both sexes: female 69 among females (68.3) and 60 among males (60.6).

As for BMI (Table 2), we can observe, according to the classification of their assigned category, that males are in their normal weight compared to females (356 vs. 228); however, in overweight it shows us a number of females (309) higher than males (218). As for obesity, we observe 83 females versus 29 males who present obesity. There is a total of two underweight males and two underweight females. It can also be observed that there is a statistically significant difference in sex for each weight category in the EQ-5D-Y utility index. 
Table 2. Study sample characteristics. EQ-5D-5L adolescents' population normative values by gender.

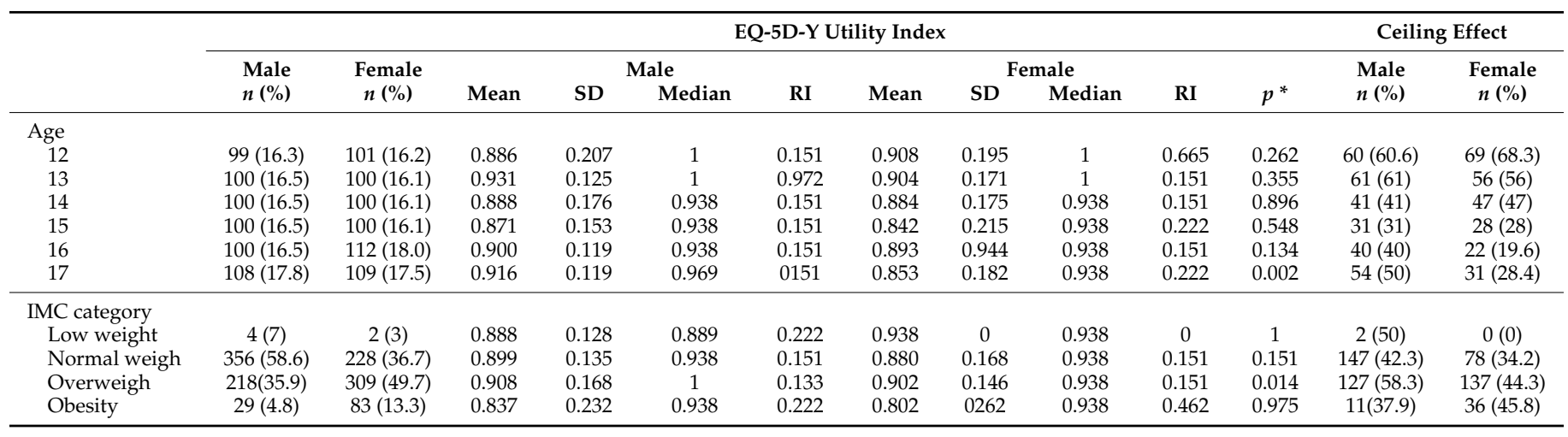

* $p$ for Mann-Whitney U test.

In Table 3, we can observe similar gender difference for each dimension. In the mobility dimension, $95.7 \%$ of the males and $94.9 \%$ of the females responded "I have no problem walking". In the self-care dimension, $95.1 \%$ of men and $92 \%$ of women responded "I have no problems washing or dressing myself". In the usual activities dimension, $78.1 \%$ of the men and $73.8 \%$ of the women responded "I have no problem performing my usual activities". Regarding the pain/discomfort dimension, $69.2 \%$ of men and $67 \%$ of women responded "I have no pain or discomfort". Finally, in the anxiety/depression dimension, $52.70 \%$ of the men and $44.1 \%$ of the women responded "I am neither anxious nor depressed". We observed a high percentage in level two of the anxiety and depression dimension in women with a percentage of $53.3 \%$ and men with $47.4 \%$. In the dimension of pain/discomfort, similar results are not shown for both sexes: $30.1 \%$ for men and $30.4 \%$ for women. In habitual activities, we observed a percentage of $43 \%$ for men and $51 \%$ for women. Regarding the dimensions of self-care and mobility, both sexes registered a percentage below $5 \%$.

Table 3. Percentage frequency distributions of EQ-5D-Y dimensions by gender and age group.

\begin{tabular}{|c|c|c|c|c|c|c|c|c|c|c|c|c|c|c|c|}
\hline \multirow[b]{2}{*}{ Level } & \multicolumn{3}{|c|}{ Mobility } & \multicolumn{3}{|c|}{ Self-Care } & \multicolumn{3}{|c|}{ Usual Activities } & \multicolumn{3}{|c|}{ Pain/Discomfort } & \multicolumn{3}{|c|}{ Anxiety/Depression } \\
\hline & Total & Male & Female & Total & Male & Female & Total & Male & Female & Total & Male & Female & Total & Male & Female \\
\hline \multicolumn{16}{|l|}{ All } \\
\hline 1 & 95.2 & 95.7 & 94.9 & $93 . .4$ & 95.1 & 92 & 75.9 & 78.1 & 73.8 & 68 & 69.2 & 67 & 48.3 & 52.7 & 44.1 \\
\hline 2 & 4.7 & 4.3 & 5.1 & 6.3 & 4.9 & 7.7 & 23.8 & 21.7 & 25.9 & 31.6 & 30.6 & 32.6 & 47 & 43 & 51 \\
\hline 3 & 0 & 0 & 0 & 2 & 0 & 3 & 2 & 2 & 3 & 2 & 2 & 3 & 4.6 & 4.3 & 5 \\
\hline \multicolumn{16}{|l|}{12} \\
\hline 1 & 92 & 90.9 & 93.1 & 92.5 & 92.9 & 92.1 & 79.5 & 79.8 & 79.2 & 75 & 70.7 & 79.2 & 69.5 & 67.7 & 71.3 \\
\hline 2 & 8 & 9.1 & 6.9 & 7.5 & 7.1 & 7.9 & 20.5 & 20.2 & 20.8 & 25 & 29.3 & 20.8 & 23 & 23.2 & 22.8 \\
\hline 3 & 0 & 0 & 0 & 0 & 0 & 0 & 0 & 0 & 0 & 0 & 0 & 0 & 7.5 & 9.1 & 5.9 \\
\hline \multicolumn{16}{|l|}{13} \\
\hline 1 & 96 & 97 & 95 & 96 & 99 & 93 & 82 & 84 & 80 & 74.5 & 77 & 72 & 62.5 & 66 & 59 \\
\hline 2 & 4 & 3 & 5 & 3.5 & 1 & 6 & 18 & 16 & 20 & 25.5 & 23 & 28 & 34 & 31 & 37 \\
\hline 3 & 0 & 0 & 0 & 5 & 0 & 1 & 0 & 0 & 0 & 0 & 0 & 0 & 3.5 & 3 & 4 \\
\hline \multicolumn{16}{|l|}{14} \\
\hline 1 & 96.5 & 95 & 98 & 94 & 95 & 93 & 78 & 78 & 78 & 69.5 & 72 & 67 & 45 & 43 & 47 \\
\hline 2 & 3.5 & 5 & 2 & 6 & 5 & 7 & 22 & 22 & 22 & 30 & 27 & 33 & 49 & 52 & 46 \\
\hline 3 & 0 & 0 & 0 & 0 & 0 & 0 & 0 & 0 & 0 & 5 & 1 & 0 & 6 & 5 & 7 \\
\hline \multicolumn{16}{|l|}{15} \\
\hline 1 & 94 & 97 & 91 & 88.5 & 93 & 84 & 72 & 76 & 68 & 61.5 & 59 & 64 & 34.5 & 36 & 33 \\
\hline 2 & 6 & 3 & 9 & 11 & 7 & 15 & 27 & 24 & 30 & 37.5 & 41 & 34 & 59.5 & 58 & 61 \\
\hline 3 & 0 & 0 & 0 & 5 & 0 & 1 & 1 & 0 & 2 & 1 & 0 & 2 & 6 & 6 & 6 \\
\hline \multicolumn{16}{|l|}{16} \\
\hline 1 & 96.2 & 95 & 97.3 & 96.2 & 94 & 98.2 & 73.1 & 73 & 73.2 & 63.7 & 64 & 63.4 & 36.8 & 50 & 25 \\
\hline 2 & 3.2 & 5 & 2.7 & 3.8 & 6 & 1.8 & 26.9 & 27 & 26.8 & 36.3 & 36 & 36.6 & 62.3 & 49 & 74.1 \\
\hline 3 & 0 & 0 & 0 & 0 & 0 & 0 & 0 & 0 & 0 & 0 & 0 & 0 & 9 & 1 & 9 \\
\hline \multicolumn{16}{|l|}{17} \\
\hline 1 & 96.8 & 99.1 & 94.5 & 93.5 & 96.3 & 90.8 & 71.4 & 77.8 & 65.1 & 65 & 72.2 & 57.8 & 42.9 & 53.7 & 32.1 \\
\hline 2 & 3.2 & 9 & 5.5 & 6.5 & 3.7 & 9.2 & 28.1 & 21.3 & 34.9 & 35 & 27.8 & 42.2 & 53 & 44.4 & 61.5 \\
\hline 3 & 0 & 0 & 0 & 0 & 0 & 0 & 5 & 9 & 0 & 0 & 0 & 0 & 4.1 & 1.9 & 6.4 \\
\hline
\end{tabular}


Table 4 shows the distribution of Peruvian adolescents according to their state of health. A total of 540 young people (representing $43.9 \%$ of the total sample) reported a perfect state of health 11111. The second most common health status was 11112, with a total of 233 adolescents, $18.9 \%$ of the sample having no problems with mobility, self-care, usual activities and anxiety/depression, but slight pain or discomfort.

Table 4. Distribution of health status.

\begin{tabular}{|c|c|c|c|}
\hline EQ-5D-Y Health Status & Frequency $(n)$ & Valid Percentage (\%) & Accumulative Percentage (\%) \\
\hline 11111 & 540 & 43.9 & 43.9 \\
\hline 11112 & 233 & 18.9 & 62.8 \\
\hline 11222 & 151 & 12.3 & 75.1 \\
\hline 11122 & 100 & 8.1 & 83.3 \\
\hline 11212 & 36 & 2.9 & 86.2 \\
\hline 11223 & 29 & 2.4 & 88.5 \\
\hline 22222 & 26 & 2.1 & 90.7 \\
\hline 11121 & 25 & 2.0 & 92.7 \\
\hline 12222 & 12 & 1.0 & 93.7 \\
\hline 22223 & 11 & 0.9 & 94.6 \\
\hline 11211 & 9 & 0.7 & 95.3 \\
\hline 12112 & 6 & 0.5 & 95.8 \\
\hline 12122 & 6 & 0.5 & 96.3 \\
\hline 12223 & 5 & 0.4 & 96.7 \\
\hline 11221 & 4 & 0.3 & 97.0 \\
\hline 21111 & 4 & 0.3 & 97.3 \\
\hline 21121 & 4 & 0.3 & 97.6 \\
\hline 11123 & 3 & 0.2 & 97.9 \\
\hline 12221 & 3 & 0.2 & 98.1 \\
\hline 11113 & 2 & 0.2 & 98.3 \\
\hline 12121 & 2 & 0.2 & 98.5 \\
\hline 21112 & 2 & 0.2 & 98.6 \\
\hline 21222 & 2 & 0.2 & 98.8 \\
\hline 22333 & 2 & 0.2 & 98.9 \\
\hline 11323 & 1 & 0.1 & 99.0 \\
\hline 12111 & 1 & 0.1 & 99.1 \\
\hline 12123 & 1 & 0.1 & 99.2 \\
\hline 12132 & 1 & 0.1 & 99.3 \\
\hline 13213 & 1 & 0.1 & 99.3 \\
\hline 21122 & 1 & 0.1 & 99.4 \\
\hline 21211 & 1 & 0.1 & 99.5 \\
\hline 21212 & 1 & 0.1 & 99.6 \\
\hline 21223 & 1 & 0.1 & 99.7 \\
\hline 22111 & 1 & 0.1 & 99.8 \\
\hline 22122 & 1 & 0.1 & 99.8 \\
\hline 23223 & 1 & 0.1 & 99.9 \\
\hline Total & 1229 & & 100 \\
\hline
\end{tabular}

\section{Discussion}

This study involved 1229 adolescents of both sexes at a secondary school age from the city of Lima. To the best of our knowledge, this is the first article that aims to provide normative data on the EQ-5D-Y in Peruvian adolescent school students.

The main finding of this study was to analyze the normative values of the EQ-5D-Y questionnaire in Peruvian schooled adolescents. Our results indicate that this self-report instrument was feasible for adolescent students aged 12 to 17 years. The EQ-5D-Y was employed in healthy schoolchildren in the general population of Sweden [25], and it was also applied in students in the city of Cape Town in South Africa to assess HRQOL in adolescents [26]. Using population health surveys in adolescents allows us to access norms of health perception references [6]. 
Regarding HRQOL, in relation to sex, adolescent males in our study show better quality of life. These results are similar to those obtained by Quiceno and Vinaccia [27], who evaluated Colombian children and adolescents and reported that males perceive better standards of living than females. Similarly, with respect to gender differentiation, males generally showed a better self-assessment of their physical well-being compared to females [28].

We also found a low incidence of serious problems reported in the different dimensions; results that are in agreement with the child/youth population of European [20,29], South Africa and Australia countries [7].

In terms of age, higher frequency is observed in the dimensions of "pain/discomfort" and "feeling sad/worried" consistently in both sexes as age increases. These results are consistent with the validation study of the EQ-5D-Y in a Spanish school [20].

A large percentage of participants reported that they had no problems in all dimensions of our investigation with an EQ-5D-Y health profile of 11111, comprising almost 50\% of our sample. This finding is consistent with previous studies used with the EQ-5D-Y. For example, $81.2 \%$ of Korean respondents reported the highest health status (11111) [30]. Likewise, in the study on the EQ-5D-Y health states in the general population in Sweden, $63.4 \%$ of respondents reported a full health status [25]. In another study on children and adolescents with asthma, the results showed that $48.9 \%$ of the respondents reported this same health status [25]. A study by [31] indicates that this may be due to the ceiling effect, because EQ-5D-Y may not be able to distinguish when the participant's health is close to full health.

In this study, we observed that overweightness and obesity are prevalent and negatively affect HRQOL. We observed a high percentage of overweight adolescents, i.e., 218 males and 309 females, and obesity in 29 males and 83 females. Our data agree with the Demographic and Family Health Survey (ENDES) of the National Institute of Statistics and Informatics (INEI), which indicated that $58 \%$ of Peruvians over 15 years of age suffer from overweight and obesity. Similarly, in the study by Lozano-Rojas [32], where the same ages were taken as in our study, they indicated a high prevalence of overweightness. Therefore, approximately one out of every two or three schoolchildren in the studied population present obesity or overweightness. The results found are almost similar to the prevalence of obesity and overweightness in adolescents aged 12 to 19 years in Ecuador [33].

On the other hand, normative data in specific populations, such as adolescents, are fundamental because they allow comparisons of HRQOL between pathological populations and the general population, which helps in the development and planning of health policies $[34,35]$. Furthermore, in the area of research, since normative data allow to assess the clinical relevance of specific treatments and interventions, they can be a useful resource for the interpretation of the outcome already indicated by the subject [36].

The finding that men have a better quality of life is very significant. Surely there are multiple reasons that explain why females have a worse quality of life than males. In this sense, a hypothesis could be proposed according to a publication prepared by the Peruvian Ministry of Education. The document points out that violence in Peru is a major social problem in adolescence (most victims are between 14 and 18 years old), with a higher prevalence in girls than in boys [37].

According to an article by Romero et al. [38], all violence, especially sexual violence, has a psychological impact. This could be a possible explanation for why girls/adolescents have worse utility values in the anxiety/depression dimension of the EQ-5D-Y.

Finally, we can confirm that, although further studies are needed to establish the cross-cultural equivalence of the instrument, the results obtained represent an important starting point for measuring HRQOL in the Peruvian population.

There is no information on the performance of EQ-5D-Y in specific populations; it was not possible to obtain additional clinical data. 


\section{Conclusions}

In conclusion, it was observed that Peruvian schooled adolescents have a favourable perception of HRQOL. Males showed better health than females. It is also observed that, as age increases, there seems to be worse HRQOL, which may be due to the physical and psychological changes that occur at this stage. As for the psychometric properties, the questionnaire presents certain problems of high ceiling effect. In order for girls to improve their health-related quality of life data, it may be of interest to include educational programmes that raise awareness of the specific issues for girls that lead to higher levels of anxiety and depression. These programmes should not only target students but also parents, family members, and the wider educational community. It would be in the interest of the political authorities to adopt concrete policies and laws to enable girls to improve their health-related quality of life.

Author Contributions: Conceptualization, S.B.-F. and M.A.G.-G.; Data curation, M.Á.H.-M.; Formal analysis, M.Á.H.-M.; Investigation, R.P.P.-C., J.C.-V. and M.M.-M.; Methodology, S.B.-F. and M.A.G.G.; Resources, J.C.-V.; Supervision, J.C.A.; Writing-original draft, R.P.P.-C., J.C.A. and M.M.-M.; Writing-review \& editing, M.A.G.-G., R.P.P.-C., J.C.A. and M.M.-M. All authors have read and agreed to the published version of the manuscript.

Funding: This research received no external funding.

Institutional Review Board Statement: The study was conducted according to the guidelines of the Declaration of Helsinki and approved by the Bioethics and Biosafety Committee of the University of Extremadura on 10 December 2020 (approval number: 162/2020).

Informed Consent Statement: Informed consent was obtained from all subjects involved in the study.

Data Availability Statement: The datasets used during the current study are available from the corresponding author on reasonable request.

Acknowledgments: The authors would like to acknowledge the secondary schools and participants who allowed us to conduct this study.

Conflicts of Interest: The authors declare no conflict of interest.

\section{References}

1. Guedes, D.P.; Villagra Astudillo, H.A.; Moya Morales, J.M.; del Campo Vecino, J.; Pires Júnior, R.J.R.P.d.S.P. Calidad de vida relacionada con la salud de adolescentes latinoamericanos. Rev. Panam. Salud Pública 2014, 35, 46-52. [PubMed]

2. Ottova, V.; Erhart, M.; Rajmil, L.; Dettenborn-Betz, L.; Ravens-Sieberer, U. Overweight and its impact on the health-related quality of life in children and adolescents: Results from the European KIDSCREEN survey. Qual. Life Res. 2012, 21, 59-69. [CrossRef] [PubMed]

3. Fryback, D.G.; Dunham, N.C.; Palta, M.; Hanmer, J.; Buechner, J.; Cherepanov, D.; Herrington, S.; Hays, R.D.; Kaplan, R.M.; Ganiats, T.G. US norms for six generic health-related quality-of-life indexes from the National Health Measurement study. Med. Care 2007, 45, 1162. [CrossRef] [PubMed]

4. Williams, A. The euroQol instrument. In EQ-5D Concepts and Methods: A Developmental History; Springer: Berlin/Heidelberg, Germany, 2005; pp. 1-17.

5. Hay, J.W.; Gong, C.L.; Jiao, X.; Zawadzki, N.K.; Zawadzki, R.S.; Pickard, A.S.; Xie, F.; Crawford, S.A.; Gu, N.Y. A US population health survey on the impact of COVID-19 using the EQ-5D-5L. J. Gen. Intern. Med. 2021, 36, 1292-1301. [CrossRef]

6. Van Reenen, M.; Janssen, B.; Oppe, M.; Kreimeier, S.; Greiner, W.J.R.E.G. EQ-5D-Y User Guide: Basic Information on How to Use the EQ-5D-Y Instrument; EuroQol: Rotterdam, The Netherlands, 2014.

7. Ravens-Sieberer, U.; Wille, N.; Badia, X.; Bonsel, G.; Burström, K.; Cavrini, G.; Devlin, N.; Egmar, A.-C.; Gusi, N.; Herdman, M. Feasibility, reliability, and validity of the EQ-5D-Y: Results from a multinational study. Qual. Life Res. 2010, 19, 887-897. [CrossRef]

8. Kreimeier, S.; Greiner, W. EQ-5D-Y as a health-related quality of life instrument for children and adolescents: The instrument's characteristics, development, current use, and challenges of developing its value set. Value Health 2019, 22, 31-37. [CrossRef]

9. Garcia-Gordillo, M.; Adsuar, J.; Olivares, P.R. Normative values of EQ-5D-5L: In a Spanish representative population sample from Spanish Health Survey, 2011. Qual. Life Res. 2016, 25, 1313-1321. [CrossRef]

10. Sørensen, J.; Davidsen, M.; Gudex, C.; Pedersen, K.M.; Brønnum-Hansen, H. Danish EQ-5D population norms. Scand. J. Public Health 2009, 37, 467-474. [CrossRef] [PubMed]

11. Hinz, A.; Kohlmann, T.; Stöbel-Richter, Y.; Zenger, M.; Brähler, E. The quality of life questionnaire EQ-5D-5L: Psychometric properties and normative values for the general German population. Qual. Life Res. 2014, 23, 443-447. [CrossRef] 
12. Ferreira, L.N.; Ferreira, P.L.; Pereira, L.N.; Oppe, M. EQ-5D Portuguese population norms. Qual. Life Res. 2014, 23, 425-430. [CrossRef]

13. Kind, P.; Hardman, G.; Macran, S. UK Population Norms for EQ-5D; Centre for Health Economics: York, UK, 1999.

14. Shiroiwa, T.; Fukuda, T.; Ikeda, S.; Igarashi, A.; Noto, S.; Saito, S.; Shimozuma, K. Japanese population norms for preference-based measures: EQ-5D-3L, EQ-5D-5L, and SF-6D. Qual. Life Res. 2016, 25, 707-719. [CrossRef]

15. McCaffrey, N.; Kaambwa, B.; Currow, D.C.; Ratcliffe, J.J.H. Health-related quality of life measured using the EQ-5D-5L: South Australian population norms. Health Qual. Life Outcomes 2016, 14, 155. [CrossRef] [PubMed]

16. Wong, E.L.-y.; Cheung, A.W.-1.; Wong, A.Y.-k.; Xu, R.H.; Ramos-Goñi, J.M.; Rivero-Arias, O. Normative profile of health-related quality of life for Hong Kong general population using preference-based instrument EQ-5D-5L. Value Health 2019, 22, 916-924. [CrossRef] [PubMed]

17. Hołownia-Voloskova, M.; Tarbastaev, A.; Golicki, D. Population norms of health-related quality of life in Moscow, Russia: The EQ-5D-5L-based survey. Qual. Life Res. 2021, 30, 831-840. [CrossRef] [PubMed]

18. Shiroiwa, T.; Fukuda, T.J.P. EQ-5D-Y Population Norms for Japanese Children and Adolescents. PharmacoEconomics 2021. [CrossRef]

19. Quiceno, J.M.; Vinaccia, S. Calidad de vida relacionada con la salud infantil: Una aproximación desde la enfermedad crónica. Psychologia. Av. Discip. 2013, 7, 69-86. [CrossRef]

20. Gusi, N.; Perez-Sousa, M.; Gozalo-Delgado, M.; Olivares, P. Validez y fiabilidad de la versión proxy del EQ-5D-Y en español. Anales Pediatría 2014, 81, 212-219. [CrossRef]

21. Herdman, M.; Badia, X.; Berra, S. El EuroQol-5D: Una alternativa sencilla para la medición de la calidad de vida relacionada con la salud en atención primaria. Atención Primaria 2001, 28, 425-429. [CrossRef]

22. Szende, A.; Janssen, B.; Cabases, J. Self-Reported Population Health: An International Perspective Based on EQ-5D; Springer Nature: Berlin/Heidelberg, Germany, 2014.

23. Brooks, R.; Group, E. EuroQol: The current state of play. Health Policy 1996, 37, 53-72. [CrossRef]

24. Badia, X.; Roset, M.; Herdman, M.; Kind, P. A comparison of United Kingdom and Spanish general population time trade-off values for EQ-5D health states. Med. Decis. Mak. 2001, 21, 7-16. [CrossRef]

25. Burström, K.; Bartonek, Å.; Broström, E.; Sun, S.; Egmar, A.C. EQ-5 D-Y as a health-related quality of life measure in children and adolescents with functional disability in S weden: Testing feasibility and validity. Acta Paediatr. 2014, 103, 426-435. [CrossRef]

26. Jelsma, J. A comparison of the performance of the EQ-5D and the EQ-5D-Y health-related quality of life instruments in South African children. Int. J. Rehabil. Res. 2010, 33, 172-177. [CrossRef]

27. Quiceno, J.M.; Vinaccia, S. Calidad de vida, fortalezas personales, depresión y estrés en adolescentes según sexo y estrato. Int. J. Psychol. Psychol. Ther. 2014, 14, 155-170.

28. Bonilla, P.U.; Ramírez, F.A.; Ureña, B.S.; Cabrera, J.S.; Romero, L.A.B. Perfil de calidad de vida, sobrepeso-obesidad y comportamiento sedentario en niños (as) escolares y jóvenes de secundaria guanacastecos. Rev. Electrónica Educ. 2010, 14, 207-224. [CrossRef]

29. Chen, G.; Flynn, T.; Stevens, K.; Brazier, J.; Huynh, E.; Sawyer, M.; Roberts, R.; Ratcliffe, J. Assessing the health-related quality of life of Australian adolescents: An empirical comparison of the child health utility 9D and EQ-5D-Y instruments. Value Health 2015, 18, 432-438. [CrossRef] [PubMed]

30. Kim, S.-K.; Jo, M.-W.; Kim, S.H. A cross sectional survey on health-related quality of life of elementary school students using the Korean version of the EQ-5D-Y. Peer J. 2017, 5, e3115. [CrossRef] [PubMed]

31. Eidt-Koch, D.; Mittendorf, T.; Greiner, W. Cross-sectional validity of the EQ-5D-Y as a generic health outcome instrument in children and adolescents with cystic fibrosis in Germany. BMC Pediatrics 2009, 9, 55. [CrossRef]

32. Lozano-Rojas, G.; Cabello-Morales, E.; Hernádez-Diaz, H.; Loza-Munarriz, C. Prevalencia de sobrepeso y obesidad en adolescentes de un distrito urbano de Lima, Perú 2012. Rev. Peru. Med. Exp. Y Salud Pública 2014, 31, 494-500. [CrossRef]

33. Yepez, R.; Carrasco, F.; Baldeón, M.E. Prevalencia de sobrepeso y obesidad en estudiantes adolescentes ecuatorianos del área urbana. Arch. Latinoam. Nutr. 2008, 58, 139-143.

34. Van den Berg, B. SF-6D population norms. Health Econ. 2012, 21, 1508-1512. [CrossRef]

35. Hawthorne, G.; Osborne, R. Population norms and meaningful differences for the Assessment of Quality of Life (AQoL) measure. Aust. N. Z. J. Public Health 2005, 29, 136-142. [CrossRef]

36. Kendall, P.C.; Marrs-Garcia, A.; Nath, S.R.; Sheldrick, R.C. Normative comparisons for the evaluation of clinical significance. J. Consult. Clin. Psychol. 1999, 67, 285. [CrossRef]

37. Claux, N. Escuelas Seguras y Libres de Violencia: Análisis de la Información de la Plataforma SISEVE; Ministerio de Educación: Lima, Peru, 2017.

38. Romero-Mezarina, F.; Dominguez-Lara, S. ¿Violencia psicológica o impacto psicológico de la violencia? El caso de la plataforma SíseVe del Ministerio de Educación (Perú). Rev. Chil. Pediatría 2020, 91, 160-161. 